\title{
ENTREVISTAA
}

CARLOS DE LA ISLA:

EL ROSTRO HUMANO

EN LA EDUCACIÓN

CONTEMPORÁNEA

Rafael González Díaz*

RESUMEN: Carlos de la Isla reflexiona sobre los retos que enfrenta la educación en el mundo contemporáneo. Su pensamiento coincide con el de otros especialistas del mundo al advertir sobre distintos peligros para las instituciones educativas, como supeditar las acciones educativas a los criterios mercantilistas. En esta entrevista, se pondera el significado de la pedagogía dialógica, el currículo oculto y la pedagogía crítica.

$$
\text { yose }
$$

ABSTRACT: Carlos de la Isla reflects on the challenges facing education today. His opinion is in agreement with various specialists worldwide warning of the dangers facing educational institutions as subjugating educational incentives to business criteria. In this interview, the significance of dialogic pedagogy, hidden syllabuses, and critical pedagogy are considered.

PALABRAS CLAVE: formación docente, filosofía de la educación, pedagogía crítica, pedagogía dialógica, justicia social.

KEY WORDS: teachers education, educational philosophy, critical pedagogy, dialogic pedagogy, social justice.

RECEPCIÓN: 10 de febrero de 2011.

APROBACIÓN: 24 de mayo de 2011.

* Departamento Académico de Estudios Generales del ITAM, la entrevista fue realizada por el profesor González Díaz (en adelante: RGD) durante los meses de noviembre y diciembre del 2010. 
La reproducción total o parcial de este artículo se podrá hacer si el ITAM otorga la autorización previamente por escrito. 


\section{ENTREVISTAA \\ CARLOS DE LA ISLA: EL ROSTRO HUMANO EN LA EDUCACIÓN CONTEMPORÁNEA}

Los grandes maestros ofrecen lecciones que no se circunscriben a la palabra escrita. Se deslizan de manera silenciosa desde la oralidad espontánea y se consolidan con la fuerza que emana del testimonio existencial, en ese "más allá" que trasciende los contenidos explícitos sobre los que versan, en apariencia, el estudio y la enseñanza. Afectan, en su sentido más extenso, la vida y el quehacer de sus alumnos, dejando una huella inequívoca y personal. Esas lecciones son el signo del encuentro y el enigma que conservamos en la memoria; sólo así puede comprenderse el afanoso ejercicio de Occidente, que no ha dejado de reconstruir y reinterpretar la figura de sus maestros, como si en esa faena no sólo se cifrara el sentido de lo que hemos recibido, sino la posibilidad de transmitir y legar los rasgos de la cultura a los hombres y mujeres que nos sucederán. En esta fascinante investigación, la oralidad ha representado la herramienta primordial de la enseñanza, mientras que la palabra escrita se ha percibido, en muchas ocasiones, como réplica imperfecta de la vitalidad del diálogo. "Desde Platón a Wittgenstein, el ideal de la verdad viva es un ideal de oralidad, de alocución y respuesta cara a cara"; 1 el maestro y el alum-

${ }^{1}$ George Steiner, Lecciones de los maestros, 2004, España, Siruela, p.12. Sería difícil dar cuenta del número de investigaciones y ejercicios de carácter religioso, filosófico, literario, sociológico e incluso científico sobre la figura del maestro, y sobre los tipos de relación que se produce con el discípulo. Desde la escuela pitagórica a Platón; de Orígenes a San Agustín; de Santo Tomás de Aquino a Ockham; de Hegel a Heidegger, todos interpretan el mensaje recibido 
no coexistiendo en el diálogo, descubriéndose para otorgar sentido a todo lo que les rodea. En esta relación educativa converge la biografía de cada uno y se desafía la comodidad que emana de la repetición de fórmulas aprendidas; supone el cultivo de un arte refinado que sabe discernir la justa proporción de inteligencia y bondad, única condición para que el alumno aprenda de su maestro, y viceversa. Por ello, muchos pueden ser instructores, pero muy pocos son auténticamente maestros.

El doctor Carlos de la Isla Veraza (en adelante: CIV), ha sostenido una prolongada reflexión sobre el sentido de la educación que se nutre de fuentes diáfanas. En sus palabras se escuchan ecos y resonancias de grandes pensadores: Ortega y Gasset, Antonio Machado, Sören Kierkegaard, José Vasconcelos, Karl Jaspers, Robert Maynard Hutchins, Martin Heidegger, Georges Gusdorf, Manuel Castells, Paulo Freire, Erich Fromm, Derek Bok, Platón, Aristóteles... Se aprecia una sincera indagación, originada en la continua labor educativa. Se trata de la reflexión original y coherente de un pensador universitario, de un filósofo de la educación que defiende sin vacilaciones una concepción crítica de la tarea educativa. Sobre todo, es la profunda reflexión de un maestro en todo el sentido de la palabra. Un hombre comprometido con la justicia e indiscutiblemente ocupado en "los saberes que son dignos del hombre libre". ${ }^{2}$

\section{La educación como mercancía}

Desde hace más de quince años se ha venido consolidado un nuevo paradigma educativo, centrando en el desarrollo de "competencias". El término remite de manera espontánea a la esfera económica y se caracteriza por enfatizar el desempeño (performance) y las capacidades (competences) del estudiante para "saber hacer en un contexto". ${ }^{3}$ En

de sus profesores, se reconocen herederos de una parte, y se muestran dispuestos a legarse en sus alumnos.

${ }^{2}$ Cic., de Orat., I, 72.

${ }^{3}$ Cfr. Posada Álvarez, "Formación superior basada en competencias, interdisciplinariedad y trabajo autónomo del estudiante", Revista Iberoamericana de Educación [http://www. rieoei.org/deloslectores/648Posada.PDF] 
sus inicios, esta noción respondía de manera puntual a la exigencia de adecuación de las acciones educativas y de capacitación con las de la industria. Esta circunstancia condicionó, en buena medida, su acceso en el ámbito educativo y explica, al menos en un sentido, por qué no ha cesado de ser controvertida. No obstante, este enfoque ha ido imponiéndose y en la actualidad está presente en casi todas las reformas educativas en Europa y Latinoamérica. No podemos soslayar que esto ha sido posible por la influencia de un grupo de organismos internacionales de carácter económico y porque el concepto se ha ido ampliando hasta incorporar una serie de "competencias" socio-afectivas, socioculturales y de comunicación que se han convertido en el estándar de lo deseable para los sistemas educativos nacionales y para los órganos internacionales, encargados de evaluar y orientar la política educativa internacional. ${ }^{4} \mathrm{Si}$ bien algunos pedagogos han levantado de manera vigorosa la voz frente a lo que consideran una reducción de la auténtica formación humana y una tecnificación de la educación, otros han querido apropiarse del concepto hasta resignificarlo.

RGD: ¿Doctor de la Isla: considera que este nuevo paradigma educativo se puede conciliar con las propuestas educativas que buscan la liberación de lo humano en el maestro y el alumno? ¿Cuáles serían los principales riesgos que identifica usted en estas propuestas educativas?

CIV: Debo confesar que el "nuevo paradigma educativo" y el desarrollo de las denominadas "competencias" me parecen una densa cortina de humo que pretende ocultar el devastador problema que aqueja a una buena parte de la educación contemporánea: el dominio del mercado sobre la dignidad de las personas. Es decir, convertir a los estudiantes en mercancías y a las escuelas y universidades en industrias de paquetes humanos producidos de acuerdo con las especificaciones del mercado. Esto significa (en términos que me gusta emplear), el triunfo casi total del Homo oeconomicus sobre el sapiens, el triunfo casi total

${ }^{4}$ Cfr. Berta Marco Stiefel, Competencias básicas. Hacia un nuevo paradigma educativo, 2008, Madrid, Narcea, pp. 29-43. 
de los grupos de poder, que ya han sometido la política (partidocracia, plutocracia), los media (mediocracia), y ahora se han propuesto manejar la "intelligentsia" como el arma más poderosa de dominación.

Es muy significativa la coincidencia: fue en Bolonia, Italia, donde se oyó el grito de protesta contra la universidad mercantilista: "Estamos hartos de ser tratados como mercancías, exigimos ser tratados como personas" (1968). Y en Bolonia, 42 años después, 29 países de la Unión Europea firman el acta fundacional de lo que se ha denominado "Proceso de Bolonia", que tiene como primer objetivo "la adopción de un sistema de títulos fácilmente comprensibles [...] a fin de promover la empleabilidad del sistema de enseñanza superior". ${ }^{5}$ Este sistema ya ha sido desenmascarado por algunos críticos, principalmente de Francia y de España. "Se trata, en realidad, de adaptar la vida universitaria a las exigencias cambiantes de las empresas y del mercado de trabajo". ${ }^{6} \mathrm{Y}$ en otra parte: "el objetivo es convertir la universidad en un Centro Profesional de Grado Superior, que nutra de mano de obra a las empresas y se haga cargo de la formación continua de sus trabajadores".? No puede ser más evidente la intención, la determinación de los agentes del mercado de apoderarse de las universidades para convertirlas en instrumentos acabados "para el atontamiento y el empleo". Aquí en México, muchas universidades han sido ya compradas por empresas transnacionales de la "educación" que cotizan en el New York Stock Exchange. Según datos de la ANUIES, "más del 93\% dan servicios deficientes y se dedican al fraude" ${ }^{8}$

El 2 de octubre de 1968, en Tlatelolco, fue impresionante el grito "Universidad, dignidad", grito conmovedor, poderoso, acallado después por las balas del sistema de mercado. Pasaron los años y ahora vuelven con más fuerza las órdenes del imperialismo internacional del dinero.

${ }^{5}$ Conferencia de Ministros, El espacio europeo de la enseñanza superior. Declaración conjunta de los ministros reunidos en Bolonia el 19 de junio de 1999. [http://www.ond.vlaanderen.be/ hogeronderwijs/bologna/links/language/1999_Bologna_Declaration_Spanish.pdf]

${ }^{6}$ Ramón Rodríguez, "Los malentendidos de la "Bölonia española", Periódico ABC, lunes 26 de enero de 2009. [http://www.abc.es/20090126/opinion-firmas/malentendidos-bolonia-espanola-20090126.html]

${ }^{7}$ Juan Antonio Valor, "El espacio europeo de educación superior”, Estudios, México, ITAM, Nueva época, vol. VIII, núm. 95, invierno 2010, pág. 221.

${ }^{8}$ Carlos de la Isla, "Ética y Universidad”, Estudios, México, ITAM, Nueva época, 2004, vol. II, núm. 69, verano 2004, pp. 7-18. 
Sin embargo, la avanzada es diferente, el campo está abierto sin enemigo a la vista. Parecería que universidades y universitarios, con pocas excepciones, han aceptado ser dóciles y obedientes al aparato de dominación. Me resultó muy significativo el eslogan de una prestigiada universidad: "Aprende a venderte". Pero no todos han claudicado: un buen número de universitarios seguirán defendiendo la dignidad, la libertad y la autonomía de la universidad. Y allí, donde el cambio ya fue firmado, seguirán pensando que "no hay nada que no pueda ser cambiado por la acción social consciente provista de información y apoyada por la legitimidad". 9

La defensa de la autonomía universitaria no significa la construcción de la universidad-torre de marfil. Por supuesto que la universidad debe conocer los problemas, las urgencias, las angustias de la sociedad, $\mathrm{y}$, no sólo conocerlas: debe estudiarlas y encontrar soluciones con sus quehaceres de investigación, docencia y extensión; pero siempre desde sí misma, con independencia y soberanía. Lo que resulta inadmisible es lo que está sucediendo: la conversión de la universidad en apéndice, en prolongación del mercado. El sometimiento de la inteligencia de la sociedad a las pasiones de los poderes políticos y económicos; la degradación de la otrora rectora y guía, a simple sirvienta. A esto los griegos lo llamaban sedición, el mayor pecado social.

Finalmente, quiero destacar el procedimiento especializado que emplean los mercaderes para obligar a los jóvenes espíritus idealistas y rebeldes a que acepten las imposiciones de la oferta mercantil: carreras demandadas, conocimientos vendibles; modelos de sumisión y entrega. El instrumento más poderoso e irresistible es el terrorismo del miedo: miedo al futuro, miedo al desempleo, miedo al mundo sin rumbo.

\section{Educar es dar a luz: "todo nacimiento es un conocimiento"}

En repetidas ocasiones se ha advertido que la tarea de la educación no se reduce a la instrucción, sino que se encuentra emparentada con el

${ }^{9}$ Manuel Castells, La era de la información, 2000, México, Paidós, vol. III, p. 394. 
asombroso acto del alumbramiento. Educar es dar a luz. El filósofo francés Georges Gusdorf lo describe de este modo en su texto Para qué los profesores?: "El conocimiento no es simple reflejo de las cosas en un espíritu; consagra el desvelamiento de una similitud de estructura entre lo conocido y el que conoce. No nacemos solos, enseña a su vez el poeta Claudel. Nacer es conocer. Todo nacimiento es un conocimiento". ${ }^{10}$ Indiscutiblemente, este desvelamiento de sentido se circunscribe a la esfera de una relación entre alumno y profesor. Experiencia sinuosa, que nunca puede predecirse absolutamente. En ella se reconocen y distinguen sus participantes y resulta condición sine qua non del tal "alumbramiento".

RGD: ¿Qué papel se puede asignar al profesor en este ejercicio que desvela la similitud entre lo conocido y el que conoce? ¿Cómo se puede comprender la educación analogada con el acto del alumbramiento? ¿La frase de Claudel se podría intercambiar, es decir, todo verdadero conocimiento es un nacimiento?

CIV: Unas palabras de don José Vasconcelos me parecen una afortunada respuesta a esta importante pregunta: "Ya es tiempo de que, dando la espalda a las técnicas tradicionales, cultivemos el parto de las almas". ${ }^{11}$ Suelo decir a los estudiantes que éste es un asunto de vida o muerte. Sólo quienes conciben y dan a luz sus propias ideas viven su vida; sólo ellos aman y defienden sus ideas como a sus hijos. Los demás, los que viven de ideas ajenas, son vividos y están muertos. Bien lo decía don José Ortega y Gasset: "No hay disyuntiva posible, todo hombre vive de ideas, la diferencia radica en que sean propias o sean ajenas; si son propias vives tu vida, si son ajenas eres vivido". ${ }^{12}$

Pienso que la gran labor del maestro es acompañar al alumno en el proceso de gestación y parto (Sócrates) de sus ideas, que son el móvil

${ }^{10}$ Georges Gusdorf, ¿Para qué los profesores, 1969, Madrid, Cuadernos para el diálogo, p. 18.

${ }^{11}$ José Vasconcelos, Pedagogía estructurativa, 2002, México, Senado de la República, p. 24.

${ }^{12}$ José Ortega y Gasset, Misión de la universidad y otros ensayos sobre educación y pedagogía, 1996, Madrid, Alianza editorial. [http://www.esi2.us.es/ fabio/mision.pdf p. 15] 
de su existencia. Colaborar con el alumno para que pueda vivir su vida en este mundo, donde los grupos de poder se han propuesto manejar a las personas como marionetas, imponiendo ideas e ideales, valores y valoraciones, modas, modos y modales. Por eso, se ha dicho que genio es el que logra ser él mismo a pesar de todos los condicionamientos del medio. La mejor imagen que encuentro del buen maestro es la del buen compañero, siempre dispuesto a caminar el camino que va de las sombras a la luz, persiguiendo, aspirando a la verdad (Platón); porque "no es tu verdad lo que importa, ni mi verdad, sino la verdad, y caminemos juntos para encontrarla", decía Manuel Machado. ${ }^{13}$

El mismo Gusdorf es muy explícito sobre el papel del buen maestro: "La educación consiste en el diálogo incierto entre dos personas de madurez diferente que dan testimonio de humanidad". Las últimas palabras insinúan que se trata de un diálogo de vidas, que es el más fecundo y verdadero, en el que no cabe la posible deformación entre la palabra y la existencia. La máxima contribución del maestro en el quehacer educativo, en este intercambio existencial, es dar testimonio de la verdad: convicciones que se convierten en vida y son vida. Decía Séneca que los buenos dichos de los filósofos son valiosos, aunque después ellos no vivan de acuerdo con lo que dicen, y es verdad, pero en el diálogo educativo la diferencia es esencial. Las mejores lecciones del buen maestro son de vida, pero sin arrogancia, sin profetismo, sin micra alguna de superioridad, sino siempre teniendo como certeza la falibilidad de su certeza. ${ }^{14}$

Creo que la afirmación de Claudel sí puede intercambiarse: “Todo verdadero conocimiento es un nacimiento". Y me parece más expresivo el término alumbramiento; no en el sentido platónico del recuerdo, sino en el sentido de la gestación, que parte del asombro y culmina en el parto, en el alumbramiento de las almas. Esto supone, como sugiere Vasconcelos, dar la espalda a las técnicas tradicionales. Es urgente superar los métodos receptivos y acríticos de la educación bancaria,

${ }^{13}$ Antonio Machado, Antología Poética. Nuevas canciones. Canciones del Alto Duero, 2003, Madrid, Edaf, LXXXV, p. 218.

${ }^{14} \mathrm{Cfr}$. Karl Popper, Conjeturas y refutaciones. El desarrollo del conocimiento científico, 2008, Barcelona, Paidós. 
de los que habló Paulo Freire; en los que el estudiante se comporta, en el mejor de los casos, como banco o custodio de los conocimientos del maestro, dador de verdades con actitud profética $y$, a veces, hasta fundamentalista. ${ }^{15}$

¡Qué distinta y hermosa la sugerencia de Kierkergaard; que el maestro se haga "discípulo de su discípulo" para entender, ser entendido y hacer posible la interlocución entre personas que pueden ser tan diferentes pero en la misma dimensión de humanidad! ${ }^{16}$ Esta actitud me parece aun más defendible que la del partero Sócrates, por los planos de igualdad y humanidad, aunque el auxilio en el parto también exalta la labor del buen maestro. La superación del magister dixit, de las actitudes proféticas de poseedor y dador de verdades, por parte del maestro; y del alumno, receptor y fiel repetidor, es más trascendental de lo que suele pensarse. Está la pedagogía para la mansedumbre, para la obediencia ciega, para el conformismo y para la aceptación de la servidumbre que tanto conviene a las manos monstruosas que manejan los poderes políticos y económicos, con frecuencia inhumanos y hasta asesinos. No hace mucho se realizó una encuesta sobre la calidad del aprendizaje-educación. Fue sorprendente que no se encontrara correlación significativa entre el tiempo y dinero empleados y el resultado de las pruebas. Se llegó a la conclusión de que la clave de las mejores evaluaciones radica en la relación activa entre maestros y alumnos. Esta interacción propicia el descubrimiento, el cuestionamiento, el asombro y hasta el compromiso. Esta demostración me parece substancial, porque muestra la ineficacia de las técnicas tradicionales y fomenta el parto de las almas. Nuestra sociedad no necesita eruditos, cerebros obesos (allí están las máquinas con todas las bases de datos); nuestra sociedad está urgida de hombres que generen, que alumbren sus ideas como se alumbran los hijos, que las amen y defiendan con pasión y conserven siempre la apertura al cuestionamiento.

Esta educación es la única que genera hombres de gran calidad humana, los que convierten en vida sus ideales, los que no sólo aman

${ }^{15}$ Cfr. Paulo freire, Pedagogía del oprimido, 2005, México, Siglo XXI.

${ }^{16}$ Cfr. S. Kierkegaard, Mi punto de vista, 1988, Madrid, Aguilar. 
la verdad, dicen la verdad, sino que son verdad (adecuación de las ideas y la vida o las ideas hechas vida). En este sentido, me parece correcto decir que la altura de un hombre se mide por la altura de sus ideales hechos vida. Estas expresiones podrían parecer que defienden el egocentrismo. Pero no, porque, ciertamente, una dimensión esencial del hombre es la dimensión social (el ser con los otros; el animal político, según Aristóteles) y el individualista egocéntrico es una mutilado social. Por el contrario, el hombre entero, el hombre humano (realizado) presente en el ideal educativo será el más comprometido con su sociedad y con su historia.

\section{La Universidad que educa en la justicia}

Esta "subjetividad" que emerge del acto educativo está vinculada con las experiencias que acompañan nuestra existencia y con los espacios donde se efectuaron. Resulta inverosímil un verdadero acontecimiento que no posea la impronta de su ejecutor ni suceso que de alguna manera nos pase inadvertido. Sólo así puede entenderse el dicho popular que reconoce en la vida a la gran maestra y que atribuye "poder" auténtico para educar a nuestra realidad cotidiana. Las palabras pueden ser "emotivas", claras, y lógicamente indiscutibles, pero las acciones tienen su propia sintaxis. Algunos estudiosos han insistido en que no hay institución educativa que no proponga de manera implícita y cotidiana un conjunto de actitudes, costumbres y valores en cada una de sus intervenciones. Incluso en aquellas que no están programadas en el currículo real. La institución educa siempre, voluntaria e involutariamente, de modo tácito pero efectivo, en cada trámite y en cada acto de gestión académico-administrativa. Nunca es neutral. En ella se prescinde de discursos, planes de estudio o programas; se hace vida no sólo lo que se predica, sino que se predica en el ejercicio más inofensivo y cotidiano.

RGD: ¿Qué importancia juega el currículo oculto para el auténtico alumbramiento educativo? ¿Qué implicaciones académico-administra- 
tivas y disciplinarias se pueden derivar de una educación que fomente en los alumnos un espíritu libre, crítico y comprometido con la sociedad?

CIV: Así como decía que el buen maestro educa mejor con lo que es que con lo que dice, así también se puede afirmar que la universidad contribuye al desarrollo, frustración o disminución de los estudiantes más con lo que es que con lo que expresa en sus idearios y objetivos institucionales. Una universidad educa en la justicia siendo justa, y es justa cuando aprecia a todos los miembros de la comunidad como dignísimas personas que realizan dignísimas labores, y no como funcionarios, operarios o mercenarios de la educación. Decía Platón en su República que una ciudad es justa cuando cada quien hace muy bien lo que le corresponde. ${ }^{17}$ Así, una universidad es justa y educa en la justicia cuando las autoridades poseen la prudencia y la sabiduría; los maestros poseen la ciencia y el don de comunicarla; los trabajadores de todas las actividades realizan sus quehaceres y son apreciados y bien remunerados; y los estudiantes alimentan y cultivan el apetito de saber y llegan al gozo de la verdad.

La universidad cultiva la rectitud y honestidad viviéndolas y sin tolerar la corrupción. La universidad educa en la libertad cuando propicia y respalda la participación e iniciativas de sus miembros, pero también controla con firmeza sus excesos; cultiva la tolerancia cuando logra el equilibrio de lo tolerable y sabe trazar la línea de lo intolerable... y así se extiende la universidad y penetra todos los espacios de la vida universitaria. Pero, con su currículo oculto, la universidad también puede pervertir cuando genera corrupción, arbitrariedad, injusticias y hasta sobornos en un sistema abiertamente mercantil. Probablemente es el problema social más grave que vivimos: enfrentarnos con el hecho de que la buena educación, promesa y esperanza de muchos mexicanos, sea convertida, en muchos casos, en fraude intolerable. Según las mediciones internacionales, México ocupa los últimos lugares en conocimientos. Seguramente, tal hecho está relacionado con el crecimiento también intolerable de la corrupción (mientras Singapur y Dinamarca son los

${ }^{17} \mathrm{Cfr}$. Pl., R., IV, 433 b. 
países menos corruptos, con 9.3 de calificación, México ocupa el lugar 98, 3.1 de calificación. Resulta lógico que Singapur aparezca en primer lugar en calidad de aprendizaje-educación). Es evidente la correlación: mala educación, mayor corrupción. Y al mismo tiempo: mayor corrupción, peor educación. Resulta muy claro y explicable la reciprocidad de la calidad educativa y la calidad de vida. Esto se manifiesta también en el comportamiento de las sociedades. Las naciones más cultas tienen una educación de mayor calidad y, al mismo tiempo, la educación de mayor calidad hace a la nación más cultivada.

Es evidente que, cuando se habla de calidad educativa, no se considera sólo la educación de grados que, según Labaní, muchas veces termina por degradar. Se trata de la educación que cultiva la justicia siendo la sociedad justa (como decía de la Universidad). El mayor impulso hacia la honradez es ciertamente una sociedad honrada que condena la corrupción. La instancia educadora más eficiente y de mayor impacto es el medio ambiente social (currículo oculto). Con razón dice el proverbio árabe: "el hombre se parece más a su tiempo que a sus padres".

¿Cómo puede la escuela hablar de dignidad humana si trata a sus estudiantes y profesores como instrumentos de producción? ¿Cómo podrá esperar respeto y admiración si aprecia más el dinero que a la personas y usa a las personas para producir dinero?

\section{EI diálogo como fuente de sentido}

Existe un punto que es especialmente importante. Se trata de los atributos que debe poseer el diálogo en la educación y las exigencias que se derivan en la práctica pedagógica. El día de hoy, nadie se atrevería a declarar que el diálogo no es especialmente importante, sobre todo en sociedades que aspiran a la democracia y la pluralidad; sin embargo, su naturaleza y sus implicaciones pueden pasar de largo o caricaturizarse de manera vulgar. Algunos lo conciben simplemente como un arte dialéctico que consiste en realizar preguntas y respuestas oportunas; otros, como un continuo flujo de opiniones sobre temas diversos que 
debe tolerar casi cualquier cosa. Nosotros reconocemos que su reflexión sobre este problemática es relevante pues ha dedicado esfuerzos importantes a dilucidar el sentido y naturaleza del diálogo en educación. No está de más señalar que esta cuestión tan trascendente supone ponderar el papel que se le debe asignar a la historia personal y comunitaria en el diálogo educativo. Desentrañar el "modo" o la manera en que se puede auxiliar al estudiante a descubrir el origen de nuestras múltiples perspectivas. Descubrir el diálogo como la herramienta primigenia de la solidaridad y el compromiso con los demás. En esta reflexión es ineludible considerar las condiciones que debe reunir el diálogo, estimar el valor que tienen los aspectos emocionales y estudiar los límites que tiene el diálogo frente al "poder" educador de la familia y los núcleos de pertenencia de los alumnos.

RGD: ¿Cómo el diálogo puede favorecer el examen de las propias ideas y las de los demás? ¿En qué sentido se puede esperar que el diálogo despierte en el estudiante las capacidades para discernir su propio destino y vocación?

CIV: Todas los aspectos y preguntas que me formula usted en este apartado son muy pertinentes, importantes y una buena inspiración para un libro de filosofía de la educación. Yo solamente me referiré a algunos aspectos de la significación del diálogo en el proceso educativo.

Toda reflexión sobre educación debe tener siempre presente el entorno social, y pienso que no es exagerado decir que las circunstancias que vivimos necesitan una consideración muy detallada y precisa para poder aportar algunas perspectivas defendibles que puedan auxiliar a los estudiantes que han de vivir, convivir - y a veces confrontarla realidad presente. Me propongo enfatizar el aspecto que me parece más relevante e influyente para poder hablar sobre esta materia y los métodos educativos. Me refiero al poder del mercado, o imperialismo internacional del dinero, con sus características y consecuencias. Me importa subrayar la explotación infame de los trabajadores con la amenaza del hambre y el desempleo como instrumento de mayor explo- 
tación al producir la infinita oferta y consecuente devaluación de la mercancía humana, hasta niveles de humillación y muerte. Este poder del mercado ya ha impuesto una pedagogía específica, orientada a la producción de los profesionistas que demanda; persigue, como producto final, al individuo versátil, especializado en funciones productivas; al instrumento dócil, sumiso y eficaz que aporta el mayor valor agregado a la maquinaria industrial.

Ciertamente, en este sistema de funciones, opuesto a creaciones, el más aplaudido, el más solicitado, el ideal es el "hombre bien redondeado", ${ }^{18}$ porque su redondez propicia la rotación perfecta técnicamente definida. Las aristas propias, la imaginación atrevida, las decisiones originales, el riesgo, el sello de autonomía, la invención asombrosa, en una palabra, la personalidad, no tiene cabida en esta estructura herméticamente armada sobre el diseño estricto de la productividad.

En el quehacer de fabricación de piezas exactas, hechas para el funcionamiento de la estructura del poder, la arquitectura educativa especializada tiene papel preponderante. A quien se busca y se favorece es al hombre obediente y sumiso al modelo. La educación, tal como funciona en la mayor parte de los países capitalistas, es el instrumento ideal para esta empresa de uniformación de los espíritus y modelado de las personalidades. Todo lo que se llama pensar y obrar está minuciosamente determinado. Así, se obtiene el hombre que se desea, con la conducta que se desea, para los fines que se desean. Es evidente que para esta producción el método obligado es el dogmático, receptivo, acrítico, profético, bancario, cuidadosamente construido para la dominación. La otra dirección, la que apunta al ser mejor de la persona, está impedida y acosada porque las personas estorban en el mundo de marionetas manejadas por los grupos que gobiernan los poderes de la dictadura mundial. Sin embargo, este es el gran reto y el único camino para que las personas puedan defenderse contra la amenaza de ser convertidas en mercancías. Los objetivos son claros y excelentes: aprecio y respeto al estudiante-persona, a su crecimiento intelectual, estético, espiritual y moral, es decir, cultivo fecundo de su entendimiento, de

${ }^{18}$ William Hollingsworth Whyte, El hombre organización, 1961, México, FCE, p. 131. 
su voluntad, de su sensibilidad, de su conciencia moral. Y, puesto que el objetivo es tan brillante, siempre debe iluminar al método, al camino para alcanzarlo.

Cuando se trata de la educación del hombre-humano el sendero es estrecho y escabroso por los inconmensurables obstáculos que se han comentado. No obstante, aunque muy difícil su recorrido, también hay que decirlo, es un camino recto e iluminado. La esencia de la buena educación es la comunicación que se establece por medio del diálogo, que traspasa el libro porque es una relación viva, en la que maestro y alumno afirman su propia existencia. ${ }^{19}$ Sin duda, el diálogo es una exigencia existencial y está inscrito en lo más íntimo del ser y del quehacer del hombre. El hombre empieza a ser hombre cuando piensa; pero, apenas piensa, inventa la palabra para comunicar su pensamiento, siente urgencia, necesidad de comunicarse. Y hasta es posible que el propio pensamiento, que muestra el salto prodigioso hasta la esencia humana, haya sido el resultado del ansia irresistible de comunicación.

El proceso dialógico implica un cambio profundo en el concepto del maestro "dador sapientísimo". En el verdadero diálogo, el maestro es un auxiliar, y "todo verdadero auxilio, dice Kierkegaard, comienza con una humillación [...] ayudar es aceptar provisionalmente no tener razón y ser ignorante de las cosas que comprende el antagonista [...] La enseñanza comienza cuando tú, maestro, aprendes del discípulo, cuando tú te instalas en aquello que él ha comprendido y de la manera como él lo ha comprendido". ${ }^{20}$ El maestro nunca considera al alumno ni retrasado, ni inferior, sino un ser humano con capacidad de genio, creador, artista, filósofo y que sólo espera el impulso humano en el diálogo o al menos quiere evitar la reclusión en las concepciones cuadradas y rígidas del saber común, forzado y oficial. La pedagogía que acompaña a la persona parte de una antropología diferente con un criterio de apreciación radicalmente distinto; juzga muy superior el despuntar de un pensamiento a la repetición textual del discurso escolar por brillante que este sea. Aspira a incursionar en lo desconocido, a imagi-

${ }^{19} \mathrm{Cfr}$. Karl Jaspers, La razón y sus enemigos en nuestro tiempo: tres conferencias pronunciadas en la Universidad de Heidelberg 1950, 1967, Buenos Aires, Editorial Sudamericana.

${ }^{20} \mathrm{Cfr}$. Kierkegaard, op. cit. 
nar aun lo imposible, a construir utopías de lo mucho mejor. Lo opuesto a este diálogo educativo son las posturas fundamentalistas y dogmáticas de los caudillos que están incendiando al mundo.

Platón, maestro del diálogo y del quehacer del maestro, describe la educación como el recorrido de las sombras a la luz. Asegura que, al final del recorrido, se encuentra la inmensa pradera de la verdad que se ensancha y se goza más con otros.

Finalmente, me parece necesario señalar la condición esencial del diálogo sin la cual no podría darse el fruto humano de la comunicación maestro-alumno. Esta condición es que el maestro no sólo trate con respeto a su discípulo (no como instrumento de trabajo o cosa que debe ser calificada), sino que muestre verdadero interés por su educación y crecimiento personal, y no sólo interés, sino auténtica estimación, sin caer en actitudes paternalistas o permisivas. Que el estudiante se sienta respetado y estimado, aun en un contexto austero y exigente, es un elemento de inmenso valor (diría yo de mayor valor educativo) que va más allá del mero aprendizaje y la cotidiana labor intelectual.

Se quiera o no, todo maestro desempeña una especie de paternidad, y así, su influencia puede ser de buen padre o de padre perverso. Esta actitud excluye en primera instancia el trato indiferente, despótico y hasta grosero por parte del maestro; trato que, por desgracia es frecuente y siempre deja una huella dolorosa en el estudiante. Es muy posible que esta percepción sea censurada y hasta condenada por muchos académicos, pero esas críticas serían una expresión espontánea del sistema dominante que se especializa en la producción de funcionarios que cumplan muy bien las funciones requeridas por el mercado.

\section{Educación para la creatividad, la conciencia crítica y la imaginación}

Finalmente, doctor de la Isla, en múltiples foros y publicaciones usted ha insistido en que la educación debe procurar el desenvolvimiento de la reflexión crítica, la imaginación, la creatividad, y sobre todo, el compromiso social en el estudiante. Estas actividades no sólo se concentran en la expansión de la agudeza intelectual, la laboriosidad y el control, 
sino en la dimensión estética y afectiva que la educación no puede ignorar sin perjuicio de la vida colectiva. Desafortunadamente, la creatividad, la imaginación y la crítica, parecen ocupar un espacio muy limitado dentro de los programas de estudio y en la vida cotidiana de las aulas. Los problemas sociales son apremiantes, mientras que la mayoría de las soluciones son las mismas. Algunos consideran que el diálogo puede fomentar la solución creativa de conflictos y despertar en los estudiantes la capacidad para discernir los símbolos, la analogía y la autenticidad.

RGD: ¿Qué se debería entender por creatividad e imaginación en educación? ¿Se puede hacer algo verdaderamente a partir del diálogo?

CIV: Creo que Fromm tiene mucha razón cuando afirma: "la enajenación es el concepto central para analizar el carácter social contemporáneo porque parece tocar el nivel más profundo de la personalidad". ${ }^{21}$ Y más adelante define: "la enajenación es un modo de experiencia en el que la persona se siente a sí misma extraña; sus actos no son suyos, no le pertenecen". ${ }^{22}$ Es imposible sentir como propios los actos impuestos. Ciertamente, la gran mayoría de los seres humanos sufren el síndrome de la enajenación por la dominación. E1 20\% más pobre de la humanidad dispone del 1\% del producto mundial, mientras que el más rico $20 \%$ posee el $86 \% .{ }^{23}$ Esto significa que la inmensa mayoría de las personas son esclavos de la necesidad, cuando escapan de la muerte. Los pobres son dominados por la necesidad, los ricos por la avaricia. Muchos millones de personas son víctimas de los media, que imponen pensamientos, valores, gustos, placeres...

Pocos pensadores, como J. Baudrillard, han percibido y expresado el procedimiento de los grupos de poder para destruir el mundo y, construir su mundo y gobernarlo: "los media captan la realidad, la despedazan y con sus añicos construyen su propio mundo en el que crean

${ }^{21}$ Erich Fromm, Psicoanálisis de la sociedad contemporánea, 1970, México, FCE, p. 97.

${ }^{22}$ Ibid., p. 105.

${ }^{23}$ Programa de Las Naciones Unidas para el desarrrollo, Informe sobre desarrollo humano 2001. [http://hdr.undp.org/en/media/HDR_2001_ES.pdf] 
leyes, modelos, ideales, aspiraciones [...] Detrás del consumo de imágenes se perfila el imperialismo de una sistema de lectura [...] lo legendario, lo que debe ser leído" ${ }^{24}$ (Medium is message) ${ }^{25}$.

Desde hace muchos años se presenta en el teatro Giovani de Praga un espectáculo de marionetas. Son hermosas figuras humanas casi de tamaño natural; cantan óperas de Verdi. Lo singular de esta representación es que, a diferencia de los títeres ordinarios que dan impresión de tener vida propia, aquí, en el teatro Giovani se ven unas enormes manos que mueven con extraordinaria habilidad aquellos personajes. Lo que no puede percibirse son los hilos que producen los movimientos. El significado es brillante y evidente: seres humanos diestramente manipulados con técnicas invisibles. Tal vez lo más importante y significativo sea el gran tamaño de las manos que representan a los grupos de poder. Debo decir que esas manos tienen también un claro aspecto de repugnancia. Difícilmente puede encontrarse una mejor representación de la realidad que vivimos. Es difícil, muy difícil, resistir la fuerza de las enormes manos; es ciertamente arduo evitar ser convertidos en marionetas. Aquí encuentro el sentido del desarrollo del pensamiento crítico, ya que es el único poder capaz de resistir los embates de los ejércitos que se proponen la dominación total. Con razón dice Castoriadis que es cada día más difícil la revolución por la democracia y por la libertad, porque ya no hay ciudadanos, sino sumisos y consumidores. Ya no hay pasión por la dignidad; y el individualismo hedonista ha producido "ese individuo apático, cínico y, con frecuencia, brutalmente aprobador y conformista". ${ }^{26}$

Sólo por el camino analítico y crítico se pueden generar los fuertes ideales que son los grandes bienes, los grandes amores que dan sentido a la existencia y hacen que valga la pena vivir la vida con entusiasmo. Sólo estas ideas dan energía para que el yo sea señor de sus circunstancias y no se convierta en sus circunstancias. ${ }^{27}$ Sólo estas ideas, dadas

${ }^{24}$ Jean Baudrillard, La sociedad de consumo, 2009, Madrid, Siglo XXI, pp. 146-7.

${ }^{25}$ Ibid., p. 117.

${ }^{26}$ Cfr. Cornelius Castoriadis, El mundo fragmentado, 1990, Uruguay, Nordan Comunidad. [http://biblioteca.itam.mx/estudios/estudio/letras24/textos1/sec_1.html]

${ }^{27}$ Ortega, op. cit., p. 16 
a luz con dolor, harán posible que la mismidad gobierne a su alteridad. ${ }^{28}$ Sólo estas convicciones podrán defender el coto sagrado, refugio del ser personal frente a las agresiones del alienum. La única manera de experimentar los actos como propios y no como "ajenos y extraños"29 o como "contrarios y enemigos" 30 es la afirmación del sí mismo, que lo convierte en soberano, que sabe bien lo que quiere, lo que decide, a dónde va y qué se propone.

Pensamiento crítico es el ejercicio de la inteligencia que piensa, analiza, cuestiona, medita y, sobre todo, juzga; es el acto más propio de la persona y que más le fortalece frente a los poderes que enajenan y producen marionetas. El pensamiento crítico en el plano social y político es la única esperanza de libertad y democracia. Dice Hutchins que una nación que no promueve la actitud crítica de sus ciudadanos está destinada a la dictadura. ${ }^{31}$ El ejercicio crítico de la inteligencia es también el quehacer por excelencia de la universidad, "recinto sagrado de la razón”, porque es el único medio para llegar a la verdad y al cultivo de la libertad. ${ }^{32}$ El cuestionamiento en nuestra sociedad es tan legítimo que resulta muy defendible cuestionarlo todo, sin llegar, tal vez, al desacuerdo y a la negación como postura. Se cuenta que don Miguel de Unamuno, al entrar al paraninfo de la universidad de Salamanca, oyó que alguien pronunciaba una conferencia y, sin saber quién hablaba ni qué decía, grito: "niego, niego". Justificó su arrebato diciendo: "hemos llegado a tal extremo de depravación que mi obligación es negarlo todo". El cuestionamiento es la salud del pensamiento, sostenía Heidegger. ${ }^{33}$

¿Por qué es urgente el cultivo de la imaginación y de la creatividad? En pocas palabras, porque es necesario inventar un mundo mejor que ciertamente es posible. Como dice la gran luchadora en el movimiento "alterglobalización", la doctora Susan George: "otro mundo es posible". Pero ella misma señala que es indispensable la protesta organizada,

${ }^{28}$ Cfr. Julián Marías, Antropología metafísica, 1983, España, Alianza Editorial, p. 224.

${ }^{29}$ Cfr. Fromm, op. cit., p. 98.

${ }^{30}$ Ibid.

${ }^{31}$ Robert Hutchins, La universidad de utopia, 1968, Argentina, Eudeba, p. 65.

${ }^{32}$ Cfr. Karl Jaspers, La idea de la universidad, 1954, Argentina, Editorial Sudamericana.

${ }^{33}$ Cfr. Martin Heidegger, Carta sobre el humanismo, 2000, España, Alianza Editorial. 
aunque tampoco basta. "Necesitamos descubrir formas de actuar juntos para crear presión porque estos bastardos [sic] han ido demasiado lejos". ${ }^{34}$ Mucha imaginación se necesita para luchar en contra de la imbecilidad de la guerra, del armamentismo, de las mafias, de las drogas, de toda clase de contrabandos hasta de material nuclear, de órganos humanos, de migrantes, de mujeres y niños, etcétera.

"Tienen que cambiar las instituciones y los esquemas mentales. La ideología del libre mercado deber ser reemplazada por análisis basados en una ciencia económica con una visión más equilibrada del papel del Estado, a partir de una comprensión de las fallas tanto del Estado como del mercado". ${ }^{35}$ Mucha y brillante imaginación es necesaria para construir una red de personas activas e informadas a lo largo del mundo, para que la empresa considere como lo más importante a las personas y al dinero como instrumento, como la Corporación Mondragón, ${ }^{36}$ para que los actores políticos abandonen el cinismo y restauren la fe en la democracia; para hacer posible el bien común, la solidaridad y la subsidiaridad; para que la familia integrada sea el alma de una sociedad, si no más rica, sí más feliz.

Lo verdaderamente imperativo es la acción inmediata, porque la globalización de la dominación y de la injusticia lleva ya una notable ventaja. Y aunque la afirmación parezca exagerada, hay que decirlo en voz muy fuerte. Todas las instituciones, especialmente las de educación superior que sigan repitiendo las mismas teorías y técnicas, que favorecen los graves vicios de esta sociedad regida por la dictadura internacional del dinero, se convierten en cómplices de la perversión.

Esto significa que no se debe continuar privilegiando la memoria que conserva y repite, sino la imaginación y la invención para presentar

${ }^{34}$ Susan George, Otro mundo es posible si..., 2007, España, Editorial Icaria-Oxfam, p.163.

${ }^{35}$ Joseph Stiglitz, El malestar de la globalización, 2003, España, Santillana, p. 468.

${ }^{36}$ La Corporación Mondragon es resultado de un vigoroso movimiento cooperativo originado en 1956 en Guipúzcoa, provincia española de la comunidad autónoma del País Vasco (Euskadi). Actualmente, la Corporación Mondragón cuenta con 85 mil empleados, 7500 alumnos de su propia universidad, un conjunto de 256 empresas y entidades, de las que cerca de la mitad son cooperativas que han sido un factor del desarrollo en la región. Incluso la influencia de este proyecto ha superado las fronteras españolas para impactar otras partes del mundo. Véase http://www.mcc.es/CAS.aspx 
RAFAEL GONZÁLEZ DÍAZ

y crear un mundo nuevo. Hay quienes afirman que el mundo siempre ha sido y será siempre igual. Esta afirmación es parte de la ideología del sistema de dominación. La verdad es que el mundo cada día cambia $\mathrm{y}$, en muchos oscuros aspectos, empeora. Sólo un ejemplo sobre la posibilidad de cambio: hace veinticinco siglos los griegos inventaron la política, especialmente el sistema en el que "el poder somos todos". ${ }^{37}$ Se siguen usando aun los nombres de los sistemas que ellos inventaron: monarquía, aristocracia, democracia, oligarquía, plutocracia... ¿No podrá existir una forma diferente de convivencia humana? ¿Se seguirá usando el término democracia como inmensa cortina para encubrir las dictaduras, las tiranías, las plutocracias existentes?

La adhesión explícita a los valores humanos universales es otra tarea esencial de la educación universitaria: "los académicos que dicen ser neutrales son mentirosos", dice la señora George, y tiene razón. Agrega: "todos los universitarios deben ser activistas a favor de la justicia y de la libertad", ${ }^{38}$ y también tiene razón. Es imposible la neutralidad en la ciencia, porque quien persigue el conocimiento verdadero de lo que se estudia está movido por el valor verdad. Si el maestro realiza bien sus evaluaciones está dirigido por el valor justicia; si trata con respeto a sus alumnos, está orientado por su dignidad.

Todos los seres humanos nos movemos por valores. Todo ser racional obra por un fin y todo fin tiene razón de bondad. ${ }^{39}$ Excelente labor realiza el maestro que muestra de la mejor manera los valores que conducen a una vida humana buena, es decir, plena.

Bien decía Derek Bok que las universidades que no se adhieren expresamente a los valores humanos universales traicionan a la sociedad, a sus estudiantes y profesores, y se traicionan a sí mismas. ${ }^{40}$ Es muy

${ }^{37}$ Cfr. Jean-Pierre Vernant, Los orígenes del pensamiento griego, 2005, España, Paidós Studio.

${ }^{38}$ George, op. cit., p. 194.

${ }^{39}$ Cfr. Arist., EN, I, 1094 a.

${ }^{40} \mathrm{Cfr}$. Derek Bok, La educación superior, 1992, Bs. As., El Ateneo. Este autor nació en Pennsylvania y enseñó derecho en Harvard desde 1958. Posteriormente, fue decano en la Escuela de Leyes y rector de Harvard en dos períodos, el último concluido en 2007. Su reflexión sobre la educación es abundante y sugerente; ha discutido ampliamente las repercusiones de la economía de mercado sobre la educación universitaria. Apenas en noviembre de 2010, la Universidad de Valencia publicó una de sus últimas obras: Universidades a la venta y La comercialización de la educación superior. En el texto se advierten los riesgos que esta práctica puede tener para los valores académicos. 
lamentable que aquella parte de la sociedad regida por antivalores o por la supuesta neutralidad esté teniendo tanto poder en el mundo. Al tratar sobre el sentido de responsabilidad social, elemento también esencial en la formación universitaria, debo subrayar que no por comentarla al final es menos importante. Así como en los derechos humanos no existen jerarquías, todos son primeros lugares, de la misma manera podemos decir de los grandes objetivos de la educación universitaria: todos son primeros lugares.

Puedo afirmar con plena convicción que las universidades que no ponen los medios para que los estudiantes tengan una auténtica responsabilidad social se convierten en cómplices de las injusticias ofensivas de nuestra sociedad. Y podemos decir que, de hecho, la mayor parte de las instituciones de educación ya han contribuido a esta separación cada vez más perversa entre los ya privilegiados y los más marginados. La concepción ética igualitaria, que es la más defendible como norma de justicia distributiva, dice "a todos por igual". No obstante, John Rawls, con sentido estricto de justicia, agrega que las diferencias se justifican cuando favorecen a los más necesitados. ${ }^{41}$

Es una evidente expresión de la infame injusticia que rige nuestra sociedad. En la distribución de recursos y oportunidades educativas, las diferencias benefician a los más favorecidos y relegan más a los ya marginados. Si a esto se agrega que en la mayoría de las universidades privadas, pero también públicas, se imparte una educación pragmática, utilitarista, que promueve el egoísmo, el resultado final es esa multitud de profesionistas que olvidan, y a veces desprecian, a aquella parte de la sociedad que fue sacrificada para hacer posible su educación.

Hay dos excelentes medios para obtener la conciencia de responsabilidad. El primero consiste en que el estudiante adquiera la evidencia de que está obligado, por justicia conmutativa -no simplemente por caridad-, a retribuir a la sociedad, por lo menos, en proporción a lo que ha recibido. El segundo es un auténtico servicio social en el que los estudiantes se relacionen vivamente con las necesidades y los necesi-

${ }^{41}$ Cfr. John Rawls, Teoría de la justicia, 2006, FCE, México. 
tados de esta sociedad, que han llegado a ser notable ejemplo de inequidad. Si no se logra este compromiso, debería darse la razón a las tesis de Ivan Illich en su obra La sociedad desescolarizada. ${ }^{42}$

Recientemente se han publicado datos muy lamentables. El Consejo Nacional de Evaluación de la Política de Desarrollo Social ha señalado que la pobreza extrema se ha duplicado en los últimos tres años. ${ }^{43}$ La población ha crecido en los pasados diez años cuatro millones más de lo estimado, lo que significa que ha aumentado la causa del alto crecimiento poblacional, que según Josué de Castro, es el subdesarrollo. ${ }^{44}$ México ha escalado diez lugares en la escala de los países más corruptos; las evaluaciones sobre calidad de la educación siguen colocando a nuestro país en los últimos lugares. Los políticos continúan mostrando su manía (locura) de poder.

Pienso que en esta crítica situación es muy oportuno afirmar con fuerte convicción: "no hay nada que no pueda ser cambiado". ${ }^{45}$ Otro mundo es posible ${ }^{46}$ con la buena educación que hemos comentado. Difícil, pero posible.

${ }^{42}$ Iván Illich, La sociedad desescolarizada, 1975, España, Barral editores, p. 50.

${ }^{43}$ Diario Oficial de la Federación, Lineamientos y criterios generales para la definición, identificación y medición de la pobreza, 2010, México, Consejo Nacional de Evaluación de la Política de Desarrollo Social. [http://medusa.coneval.gob.mx/cmsconeval/rw/resource/coneval/ med_pobreza/DiarioOficial/DOF\%20lineamientos\%20pobrezaCONEVAL_16062010. pdf?view=true]

${ }^{44}$ Cfr. Josué de Castro, Ensayos sobre el subdesarrollo, 1972, Buenos Aires, Siglo XX.

${ }^{45}$ Castells, op. cit., p. 394.

${ }^{46}$ George, op. cit., p. 8. 